University of North Florida

UNIVERSITY of

NORTH FLORIDA.

UNF Digital Commons

2005

\title{
Mr. ATOD's Wild Ride: What Do Alcohol, Tobacco, and Other Drugs Have in Common?
}

David T. Courtwright

University of North Florida, dcourtwr@unf.edu

Follow this and additional works at: https://digitalcommons.unf.edu/ahis_facpub

Part of the History Commons

\section{Recommended Citation}

David T. Courtwright, "Mr. ATOD's Wild Ride: What Do Alcohol, Tobacco, and Other Drugs Have in Common?" Social History of Alcohol and Drugs 20 (2005): 105-124, https://alcoholanddrugshistorysociety.files.wordpress.com/2014/06/shadv20n1xcourtwright1.pdf

This Article is brought to you for free and open access by the Department of History at UNF Digital Commons. It has been accepted for inclusion in History Faculty Publications by an authorized administrator of UNF Digital Commons. For more information, please contact Digital Projects.

(C) 2005 All Rights Reserved

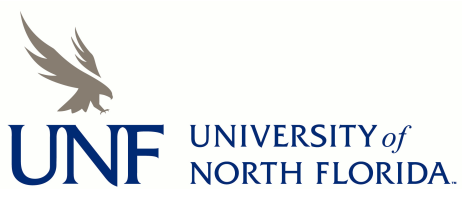


The Social History of Alcohol and Drugs 20 (2005): 105-40.

\title{
ADHS FORUM
}

\section{Mr. ATOD’s Wild Ride: What Do Alcohol, Tobacco, and Other Drugs Have in Common?}

\section{David T. Courtwright}

\begin{abstract}
All researchers agree that individuals can become intoxicated by and dependent on alcohol, tobacco, and other psychoactive drugs. But they have disagreed over whether, and to what extent, drug pathologies comprise a unitary medical problem. Most critically, does addiction have a biological common denominator? Consensus on this question has shifted back and forth. In the late nineteenth and early twentieth centuries, physicians often studied and treated various drug addictions together, working under the "inebriety" paradigm. By the mid-twentieth century the inebriety paradigm had collapsed. Tobacco and alcohol had split off, both in the medical research community and in western popular culture. This article argues that neuroscientific, genetic, epidemiological, and historical evidence helped to reunify the addiction field in the late twentieth century. A new unifying paradigm emerged, variously called chemical dependency, substance abuse, or simply ATOD—alcohol, tobacco, and other drugs.
\end{abstract}

WhEN YOU WRITE GLOBAL DRUG HISTORY, you quickly discover the limits of your knowledge, and you rely on the work of others. Many of the scholars whose research has guided and inspired me are present this evening. I first want to express my debt to you and my gratitude for the opportunity to address you. I am truly honored.

My title, "Mr. ATOD's Wild Ride," is an anagrammatic play on a celebrated episode from Kenneth Grahame's The Wind in the

David T. Courtwright is John A. Delaney Presidential Professor in the Department of History at the University of North Florida. He delivered "Mr. ATOD's Wild Ride" on May 14, 2004, as the Keynote Address of the International Conference on Drugs and Alcohol in History at Huron University College, London, Ontario. 
Willows. Mr. Toad, you will recall, has a thing for fast machines. He is, in fact, unable to control himself around them. They "intoxicate .. . his weak brain." Disguised as a washerwoman, Toad commandeers a motor car and goes hurtling down the road. When its owner and chauffeur imprudently try to stop him, he sends the car veering across the road, smashes into a hedge, and goes flying through the air.

Mr. Toad's wild ride has inspired a Monty Python movie and an amusement-park ride in my home state of Florida. Toad's ride has also inspired me by suggesting a metaphor for shifting western and, more particularly, Anglo-American, attitudes toward ATOD: alcohol, tobacco, and other drugs. In the last century those attitudes have, like Toad's car, veered sharply. They have gone from a tendency to see ATOD and their pathologies as linked phenomena, then to a tendency to see them as separate phenomena, then, in the last thirty years, to see them again as linked. I've sketched these shifting attitudes toward ATOD as a pendular timeline (Figure 1). It's not an exact timeline, for most of the events depicted occurred over many years, rather than during a single year. But it makes the point. Consensus on this question has lurched from one side of history's road to the other and then back again.

I use the words "tendency" and "consensus." I don't think that all experts shared these attitudes at any given point in time, or that the swings of opinion occurred without dissent. What I propose is a sketch of "governing ideas." Governing ideas are "cognitive bundles" of related concepts that have had "considerable intellectual appeal and at some point succeeded in capturing the attention, imagination, and actions of the broad population" (Gerstein and Harwood 1990, 42). Specialists framed problems in certain ways, and their views percolated into popular consciousness and language. In the 1960 s continental drift and plate tectonics triumphed as governing ideas in geology, and before long school children were getting watered-down versions in their earth science lessons. New ideas about the nature and management of compulsive alcohol and other drug use spread in comparable fashion-with, as Sarah 


\section{Governing Ideas about Alcohol, Tobacco, and Other Drugs Emphasis on ATOD Commonalities Emphasis on ATOD Differences}

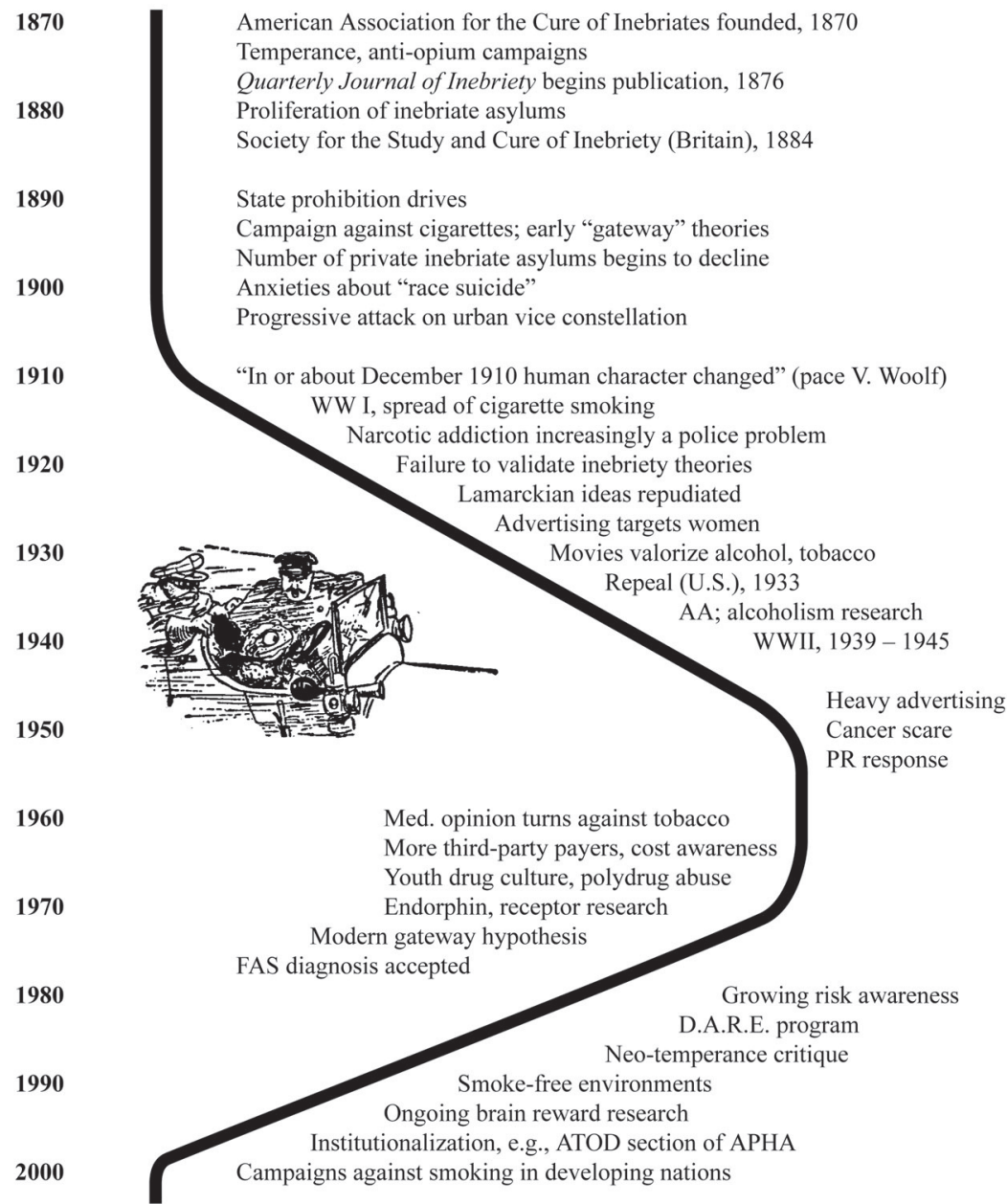

Figure 1. Governing Ideas about Alcohol, Tobacco, and Other Drugs

Tracy points out, input from patients and their families along the way (Tracy 2005).

So what were the governing ideas about psychoactive substances? In the late nineteenth century, the key medical concept, at least in Britain and most of North America, was inebriety. Many physi- 
cians who treated alcoholics and narcotic addicts held that these conditions were manifestations of a more general mental disorder called "inebriety." The Keeley Institute, a large treatment franchise, advertised that the "person addicted to liquor or drugs is a victim of a ravishing disease," which may nevertheless be successfully treated "by the famous Keeley Treatment" (Keeley Institute 1921, emphasis added). The treatment regimen for residential Keeley patients - who might be dependent on alcohol, or narcotics, or both-required abstention from tobacco and even caffeinated beverages, understood as insalubrious habits likely to trigger relapse (White 1998, 55).

The inebriety theory drew on three other popular nineteenthcentury medical ideas. These were neurasthenia, or nervous weakness; diathesis, or constitutional predisposition to chronic disease; and degeneration, or transmission of morbid deviations across generations. Thomas Crothers, a representative figure, taught that alcohol and other drugs had pathological effects on the nervous system. The effects varied. Those suffering from neurasthenia, such as exhausted "brain workers," were particularly susceptible. Also susceptible were those born with a nervous diathesis. Whether the vulnerability was environmental or constitutional-in our terms, whether it was due to stress, genes, or both-alcohol and other drugs left a permanent pathological impression on inebriates' nerves. The repeated administration of a drug intensified this impression into a "morbid craving," the heedless, self-destructive pursuit of the substance that seemed the common denominator of all inebriate behavior (Crothers 1902).

Once acquired, the trait of inebriety could be passed on as degenerate constitutional tendencies. The process was often one of sinister transmogrification. The drunkard's child might be an opium addict, his grandchild an epileptic, his great grandchild a congenital idiot. Though inebriate degeneration might assume many forms, its final end was always ruin. It was crucial, therefore, to keep the young from acquiring inebriate habits, for their sake and for posterity's. Drugs were literally "germ poisons" that threatened the "race" by 
corrupting sperm and ova. Caleb Saleeby, a prominent English eugenicist and opponent of both tobacco and alcohol, went so far as to argue that alcoholics should be prevented from procreating (Armstrong 2003, 27-42; Woiak 1998).

Other temperance advocates concentrated on preventing drug use from spreading within, rather than across, generations. They made tobacco a particular target, for tobacco often led to drink and other drugs. The most trenchant of the early "gateway" theorists was Charles Towns, a lay addiction specialist. Except for a few women, Towns wrote, every alcoholic and addict he treated had a history of excessive tobacco use. Smoking magnified any personal predisposition toward inebriety, "because the action of tobacco makes it normal ... to feel the need of stimulation." Tobacco's irritating effects could be blunted by alcohol, on which the smoker in turn became dependent. Then came narcotics to allay hangover and other effects of drinking. "Cigarettes, drink, opium is the logical and regular series" (Towns 1915, 153).

Towns set forth his views in Habits That Handicap (1915), a slender little book that was perhaps the most prescient work about ATOD linkages to appear in the early twentieth century. Towns was an intuitive sociologist who saw that smoking was socially conducive to other forms of addiction. Boys sought out the back rooms of pool halls and saloons to smoke in secrecy, and there they also learned to gamble and drink. Better-educated men who refrained until they entered college found themselves "out of it" if they didn't light up. Sociability was tobacco's most seductive attraction, and its social utility made it that much harder to quit. Worse, tobacco's use scandalized others and tempted them to follow the same path to intoxication. "The very openness and permissibility of the vice," Towns decided, made tobacco the worst of the drug habits (Towns 1915, 172).

When Towns wrote those words the first ATOD paradigm was near-actually, just past-its zenith. As John Burnham and Caroline Acker have shown, beliefs about the pathological links among drugs and other vices had yielded practical political conse- 
quences in the broad-gauge progressive campaign against the urban "vice constellation." The same reformers who went after narcotics and alcohol often tried to suppress cigarettes, prostitution, pornography, and gambling. Essentially, they understood vice as a package deal (Burnham 1993; Acker 2002).

Even in the 1910s, however, forces were emerging that would spell the end of the first inebriety movement. In fact, by the late 1930s, the idea of biosocial linkages among alcohol, tobacco, and other drugs had all but disappeared. True, it persisted in otherwise disparate groups that shared an unremitting ideological hostility to all psychoactive drugs. Nazis, Mormons, and Evangelical Protestants come to mind. Total sobriety makes for strange bedfellows. But in both western medicine and in western popular culture, alcohol and tobacco effectively split off from other drugs, to the point that the ordinary understanding of the word "drugs" came to exclude, rather than include, these substances. Anyone who asked North American high school students in the 1940s what "drugs" meant would have been told they had something to do with hospitals or dope fiends. Why did this happen?

The collapse of the unifying inebriety theory is a good place to begin. Briefly, its proponents never delivered the scientific goods. They never showed, at the level of cellular pathology, the common mechanism by which drugs caused lasting neurological damage in susceptible persons, or caused such symptoms as withdrawal and craving. The few specific hypotheses, such as Ernest Bishop's antitoxin analogy, were falsified. No one ever discovered the mechanism by which alcohol and other drugs damaged germ plasm. The Lysenko episode aside, belief in Lamarckian ideas collapsed. Western researchers abandoned the assumption that acquired traits could be passed on to offspring. The Nazi horrors and abuses such as involuntary sterilization gave eugenics a bad name. Researchers quit generalizing about alcohol as a "race poison," or generalizing much about races at all.

What midcentury researchers did do, with the support of both Alcoholics Anonymous and the alcoholic beverage industry, was to 
focus on alcoholism. Howard Haggard and E. M. Jellinek's widely read 1942 book, Alcohol Explored, exemplified the new approach. Alcoholism was still a disease, to be sure, but a specific disease manifest in a minority of users who could not control their drinking. Alcohol itself was not inherently toxic. The authors found no evidence that alcohol damaged offspring, either through heredity or teratogenesis. Indeed, for the majority of drinkers, alcohol was merely a harmless "social condiment." The old inebriety view of alcohol-in Norman Kerr's words, that it was a "poisonous narcotic beverage" —now seemed passé (Roizen 2004; Haggard and Jellinek 1942, 12, 208; Kerr 1887, 2).

The widespread social use of alcohol by physicians and their spouses could only have made these new views more congenial. The same may be said of tobacco. The now-infamous Camel claim, that doctors smoked Camels more than any other brand, was false. But the deeper premise - that doctors smoked a lot of cigarettes, at least before the first big cancer scare in the 1950s-was true. Personal use tended to blind physicians and researchers to the harms of tobacco and to its links to other patterns of drug use.

They weren't alone. As millions of ordinary men and women took up cigarettes, the idea that smoking necessarily led to intoxicating drugs faded. Many of the new smokers were patriotic veterans of the Great War, and they had received their cigarettes from reputable organizations like the Red Cross (Tate 1999). Airplane pilots even dropped cigarettes to doughboys in advanced posts. A few years ago, working in the Library of Congress, I found a gouache drawing with the unlikely title "Colonel Sir Valtravers Plantagenet gladly accepts a light, during a slight lull in the barrage, from a private in the Benin Rifles" (Figure 2). I proposed the illustration for Forces of Habit, only to have one of my editors veto it. She said it played on racial stereotypes. It certainly did, but that's why I thought it worked. It made my point that cigarettes had transcended the conventional social boundaries of race and class. Only the barrier of gender remained, and that gave way in the 1920 s and 1930s, thanks to clever advertising and the influence of the movies. 


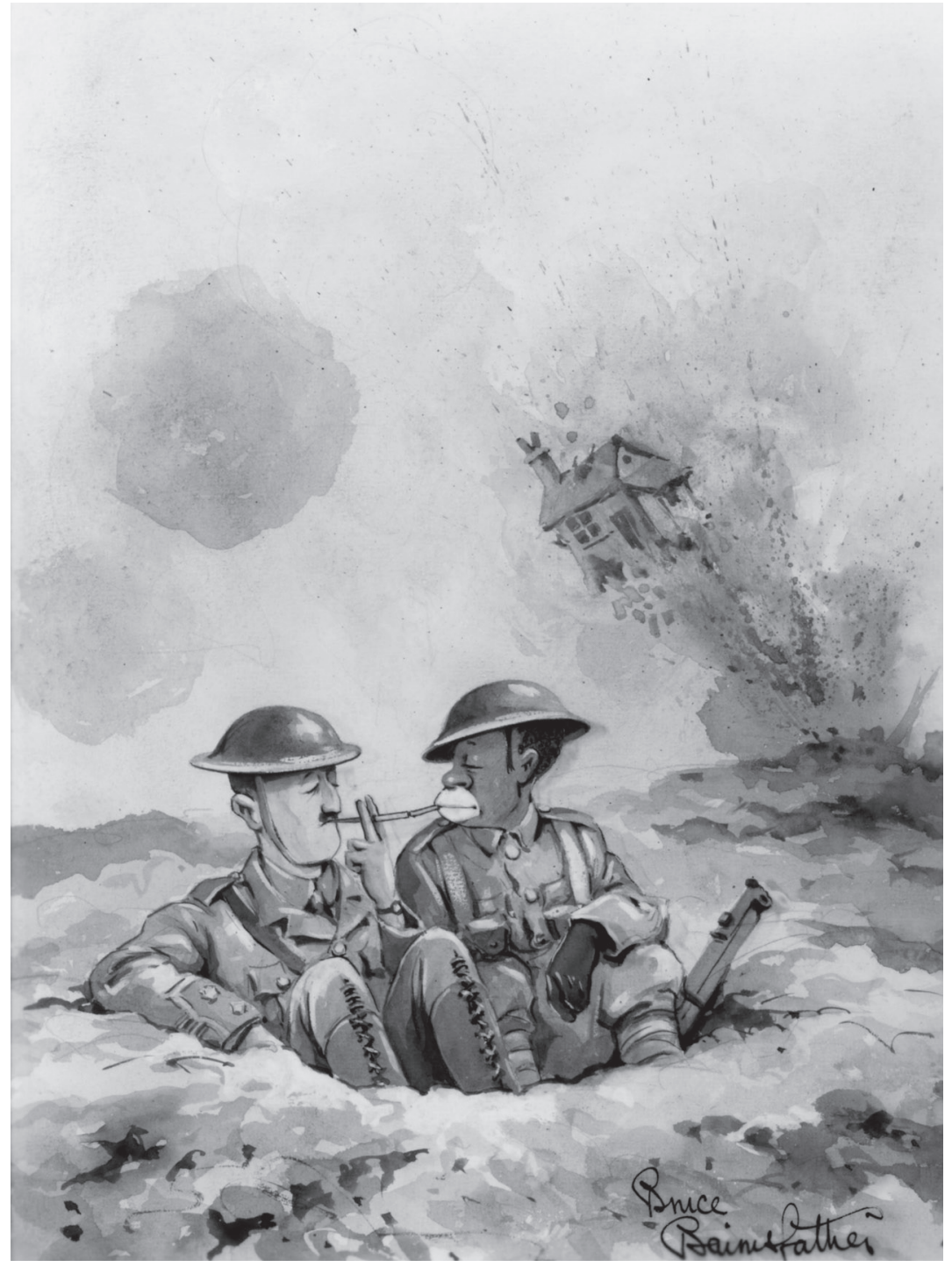

Figure 2. Gouache drawing in the Library of Congress: "Colonel Sir Valtravers Plantagenet gladly accepts a light, during a slight lull in the barrage, from a private in the Benin Rifles."

In the late 1930s, 1940s, and 1950s, cigarette smoking among adults became so widespread as to be unremarkable, unexception- 
able, socially invisible. Smoking paraphernalia spread everywhere. Ash trays sprouted on bistro tables and soda-fountain counter tops, cigarette lighters appeared on car dash boards, and, if you wanted to make a statement, you could even buy your own ring-cigarette holder. Matchbooks, which doubled as a convenient form of advertising, were the most common sort of paraphernalia. Their covers show how culturally Janus-faced smoking had become. Some of them already nod back in the direction of the underworld, the adult world of risqué jokes and taverns and extra-marital sex. But there's also the shining upperworld of modernity: nationalism, fast transportation, electrified communication, and consumer conveniences. Smoking is up-to-date and linked to two other kinds of licit drugs, alcoholic and caffeinated beverages. Matchcovers even pitched products designed to ameliorate the consequences of smoking, such as cough drops-an aspect of a broad phenomenon that economists call "externalities" and I call "problem profits."

Both the masses and elites smoked. Elite smoking habits were so well known that cartoonists could use them as shorthand, identifying Winston Churchill by his long cigar, FDR by his cigarette holder, and Douglas MacArthur by his corncob pipe. Such personal use of tobacco had nothing to do with "real" drugs. Indeed, pamphlets at the Lexington Narcotic Hospital told new patients where to buy their smokes. Clouds of smoke hung over AA meetings. By contrast, the Keeley Institute had refused to accept cigarette smokers. The late-nineteenth-century view was that they had slipped into the use of alcohol and narcotics easily, and that, while they smoked cigarettes, they could not abstain from other drugs.

The decoupling of alcohol and tobacco from other drugs was no accident. It was at least partly the result of a deliberate campaign by powerful and fiscally important industries, which spent millions on advertising and public relations to promote and defend their products. These industries had a huge advantage. Ethical pharmaceutical manufacturers couldn't advertise drugs like narcotics or stimulants, except within relatively narrow professional medical circles. Folk or bohemian drugs like marijuana spread by word of 
mouth. Virtually the only advertising they generated was official warnings aimed at discouraging their use. Makers of alcohol and tobacco, however, were free to present their products as innocent and salubrious, and to do so to a mass audience. Guinness famously reduced the message to a slogan: "Guinness is good for you."

Abetted by the movies, alcohol and tobacco ads played up themes of youth, glamor, athleticism, and conviviality. True, the manufacturers could never fully escape or suppress the evidence of their products' toxicity and addictive potential. But they could hire public relations experts to counter unwelcome news. Hill and Knowlton, America's leading public relations firm, worked for both the Licensed Beverages Industries, Inc., and the cigarette manufacturers. Hill and Knowlton managed the Tobacco Industry Research Committee, a public relations operation intended to assuage public anxieties by raising doubts about the cancer link and fostering the impression that the industry was actively investigating any potential health problems. The British industry created a comparable organization. It challenged purely statistical studies and called attention to the industry's funding of lung-cancer research. The implicit message: if there's something bad in cigarettes, the scientists in the white coats will find it and take it out, so relax and carry on smoking (Courtwright 2005).

Of course, there were plenty of honest researchers in the midtwentieth-century, researchers who operated independently of the tobacco and alcoholic beverage industries. But they all faced the problem of information glut. Another, quotidian reason that the first ATOD paradigm unraveled was specialization. To cope with the literature explosion, researchers had to concentrate on one drug, or one aspect of one drug. I suspect everyone here has come up against this problem. When I began my dissertation on opiate addiction, I found an international bibliography, The Pharmacology of the Opium Alkaloids (Krueger, Eddy, and Sumwalt, 1943), that was full of clinical, epidemiological, and pharmacological material. Too full: there were nearly 10,00o entries. I remember thinking, 
"They've got to be kidding." Any notion of studying more than one type of drug in one country quickly departed.

I sank my particular posthole in the mid-1970s and dug in it contentedly for some time. Looking back over thirty years, I'd say the biggest surprise has been the rebirth of inebriety. It doesn't go by that name, or any single name. It's been called chemical dependency, substance abuse, and ATOD abuse, among other terms. But there's no mistaking its presence. Bill White, a clinician and historian, said it best in Slaying the Dragon. "For most of the 2oth century," White wrote, "no conceptual umbrella existed to help the field understand and intervene in the destructive use of all psychoactive drugs. The most seminal event in the modern era of addiction treatment was the reformulation of terms analogous to the earlier concept of inebriety." Researchers and clinicians rethought the addiction experience, emphasizing its commonalities and looking for integrated theories and treatment approaches. The same conceptual shift, White argued, was linked to the "culture's more temperate relationship with alcohol and its growing rejection of tobacco" (White 1998, 287-88).

So attitudes toward ATOD have swerved backed to the other side of the road. The big increases in youthful and polydrug abuse undoubtedly had much to do with this switch. So did the growing western cultural awareness of, and aversion to, health risks of any variety. But I want to highlight three "internalist" factors: discoveries in neuroscience, genetics, and new epidemiological findings.

Since the 1960s, scientists have worked out, in increasingly refined detail, how psychoactive drugs affected the mesolimbic dopamine system. This is the neural reward pathway that originates in the ventral tegmental area at the base of the brain. From this region the neurotransmitter dopamine carries messages forward to the nucleus accumbens, a key pleasure center beneath the frontal cortex. Experiments on animals that have been taught to self-administer drugs have shown a sure-fire method for eliminating addiction: just destroy this system. Of course, there are minor drawbacks, like loss of interest in food. That's why drug addiction is so stubborn and 
insidious. It represents, at least on one level, the chemical hijacking of the brain's most basic and ancient system of reward and motivation.

There's more to the story than a single neural pathway. Drug administration also sends messages to the amygdala and hippocampus, which are important for forming memories and cues associated with craving and relapse. It's also true that drugs work in different ways. Opiates and alcohol stimulate dopamine production directly, while cocaine blocks its reuptake. But the bottom line, to quote a recent literature review, is "different drugs, same ultimate effect" (Nestler and Malenka 2004, 84). That goes for licit and illicit drugs, and sometimes for licit and illicit drug treatment. Naltrexone, an antagonist that blocks opioid receptors and which has been used to treat narcotic addicts, has shown promising results in preventing craving and relapse among alcoholics (Rawson et al. 2000). Though the degree of Naltrexone's therapeutic benefit is still under investigation, and though it may not help the severest alcoholics (e.g., Krystal et al. 2001), the findings do suggest that at least some of the opioid receptors are involved in both types of addiction. Also intriguing is the fact that PET brain scans of compulsive gamblers shown slot machines look very similar to those of cocaine addicts shown white lines on a mirror. Compulsive gambling and drug addiction have many symptomatic parallels, and there is a good deal of comorbidity: heavy gamblers are more likely to be ATOD users, and vice versa (Petry 2002).

That's not to say that all forms of addiction can be reduced to a single neural pathway, or that drug use can be understood apart from its social and cultural context. When critics (e.g., Satel 2002) accuse the National Institute on Drug Abuse of being obsessed with the "chronic relapsing brain disease model," to the exclusion of other approaches, they make a fair point. Even Alan Leshner, the former head of NIDA who did so much to popularize the neurological model, wrote that "addiction is not just a brain disease. It is a brain disease for which the social contexts in which it has both developed and is expressed are critically important" (Leshner 1997, 
46). Still, one does not have to be a biological reductionist to grasp the historical significance of this research trend or to understand how it reinforces the idea that psychoactive drugs have more in common than was once thought. The progressives had a point. Vices are linked.

The predisposition toward vice may also have a genetic basis, if not necessarily a Lamarckian one based on our ancestors' poisonously altered germ plasm or otherwise wickedly acquired characteristics. "Several twin studies," to quote a recent JAMA review, have shown "significantly higher rates of dependence among twins than among nontwin siblings and higher rates among monozygotic [identical] than dizygotic [nonidentical] twins." Heritability measures have been estimated at 0.34 for men dependent on heroin, 0.55 for men dependent on alcohol, 0.52 for women dependent on marijuana, and 0.61 for men and women who are regular cigarette smokers (McLellan et al. 2001). The inebriety theorists' hunch, that individual reactions to alcohol, tobacco, and other drugs vary, depending on innate neurological susceptibility and family history, have apparently been borne out for several different substances. Some people are disposed to find certain kinds of drug use more rewarding, or less toxic, or both. Addictive predispositions may overlap. Studies have shown that those with a genetic predisposition for alcohol dependence are also more likely to have problems with pathological gambling (Petry 2002, 185).

It is possible that the correlations are due, not so much to neurological susceptibility per se, but to personality traits that are also partially inherited. Children, especially male children, who lack self-control and future orientation, who are impulsive, insensitive to others, and less intelligent, are more likely to experiment with drugs. In fact, this same constellation of traits predicts a wide range of illegal behaviors (Gottfredson and Hirschi 1990). Loutish thrill-seekers will end up with more ATOD problems for the same reason they end up with more jail time for smash-and-grab thefts and joyriding in stolen cars. Personality traits increase the odds of forbidden experimentation, and experimentation increases the 
odds of (indeed, is a prerequisite for) long-term conditions like addiction.

Having said this, I should add that I've long had reservations about the concept of an "addictive personality," whether defined in terms of neurological susceptibility or broader antisocial behavior. If personality is so important, why were most American opiate users middle-aged, middle-class females in the nineteenth century and younger, lower class-men in the twentieth? Or why were they once mostly white and Asian and, then, within the space of two or three decades in the mid-twentieth century, mostly black and Hispanic? Were the addictive personality traits "jumping genes" that hopped from one group to another? (Courtwright 2001a, 6, 152-55). Obviously, specific social circumstances-what doctors prescribed, which immigrants were moving into drug-infested slums-mattered a great deal. One might even say that it is the historian's indispensable task to point out what those specific circumstances were, and how they changed over time. That said, the question of inherited vulnerability has clearly reemerged in the addiction research field; it has important implications for etiology, prevention, destigmatization, and treatment; and it has reinforced the idea that a range of compulsive behaviors may have common biological elements. ${ }^{1}$

The third field that has contributed to the rebirth of the ATOD paradigm has been epidemiology. Even allowing for some beneficial cardiovascular effects from moderate wine drinking, statisticians documented, with increasing precision, the elevated risks of accidents when drinking, and the risks of chronic disease for heavy drinkers. The more one drank, the greater the risks-a dose-response finding central to the emergence of the alcohol public-health paradigm in the mid-1970s (Roizen 2004; Room 2004). The smoking data were even more damning. The relentless accumulation of health evidence, and the related economic evidence of heavier health-care costs, undercut the efforts of alcohol and tobacco companies to portray their products as benign nondrugs. It also explains why these same companies have increasingly 
sought to exploit markets in developing countries, where government regulations are fewer and consumers tend to be less wary.

In the mid-1970s, Denise Kandel and others put the gateway theory on a much firmer epidemiological basis. They emphasized the risk of advancing from licit to illicit drugs. Not all smokers or drinkers did so, but their odds of progression were far higher than abstainers' - a finding that held up in France, Israel, and Japan as well. As a recent RAND study shows, adolescent smokers were at especially high risk (Kandel 2002; Ellickson 2002). The same study showed early smoking to be an excellent predictor of subsequent social problems. When the politician and novelist Jeffrey Archer was sent to Belmarsh prison following his 2001 perjury conviction, practically the first thing he noticed was the ubiquity of smoking. It took only a few strip searches before it dawned on him that the inmates, especially the repeat offenders, were also heavily involved in the illicit drug culture (Archer 2003).

The process by which young smokers moved on to other drugs involved three types of causes-social, learning, and neurochemical. None was necessary or sufficient, but all increased the likelihood of other drug use. Socially, "enabling factors" played a key role. These were the influences Charles Towns had in mind when he described boys lighting up in the pool hall. Adolescent smokers were more likely to be part of peer groups in which alcohol and other drugs were available. They were more likely to become curious about them, to observe how they were used, and to receive praise if they tried them for themselves. Ditto other problem behavior, such as petty theft or skipping school.

Learning also played a part. Smoking is an acquired skill, something neither intuitive nor pleasant on first trial. By learning to inhale tobacco smoke, individuals acquired the behavior necessary for consuming marijuana and other smokable drugs. Because underage smoking was illegal, adolescent tobacco users also learned to develop masking behaviors that served to hide forbidden drug use. 
Then there is the effect of tobacco itself. Smokers have lower levels of monoamine oxidase-B, the enzyme responsible for breaking down dopamine in the brain. They can sustain higher levels of dopamine for longer periods of time, particularly if they continue smoking. More dopamine means more pleasure: tobacco works synergistically with alcohol, cannabis, cocaine, and narcotics to provide a sustained high. Hence alcohol and other drug users tend to smoke more heavily. The reverse is also true. Alcohol, a depressant, mitigates some of the adverse effects of smoking, such as increased heart rate. And alcohol activates nicotine-metabolizing enzymes, which makes it necessary to consume more tobacco to achieve the accustomed effect (Courtwright and Courtwright, forthcoming). ${ }^{2}$

In brief, the neuroscientific and epidemiological studies suggest that drug consumption is synergistic and crosses licit-illicit lines. I found that out for myself when I began, in the opening chapters of Forces of Habit, to describe when various drugs had become important commodities. We have all been taught that description is easier than analysis. I found the opposite to be true. The analytic chapters-how medical drugs caught on in popular culture, why drugs were ideal products, how drugs financed empires and exploited colonial labor, why elites finally imposed restrictionsturned out to be much easier to write. The biggest challenge was describing the globalization of drugs, a process I called the "confluence of the world's psychoactive resources" (Courtwright 2001b).

I thought I'd tackle one drug at a time. I'd describe the spread of alcoholic beverages, then tobacco, then caffeinated beverages- "the big three" - then move on to opiates, cannabis, coca products, and synthetics. Try as I might to keep my drug histories compartmentalized, they kept sloshing over onto one another. "Confluence" really is le mot juste. The Chinese, for example, learned to smoke tobacco, then tobacco mixed with opium, then refined opium. When early modern European sailors went on liberty, pipe in one hand and drink in the other, they instructed natives in the art of smoking and drinking. They taught that these two novel practices went together. (As, neurochemically, they in fact do.) I discovered that early 
modern European coffee houses were seldom simply coffee houses. Patrons could purchase all sorts of psychoactive products, from chocolates to exotic liqueurs. They could also smoke, which was good for business, because, we now know, smokers metabolized caffeine much faster than nonsmokers. I also found that complex, overlapping patterns of consumption had developed in Europe's many colonies. In 1945, when Ho Chi Minh declared Vietnamese independence, he condemned the French for foisting opium and alcohol on his people. I suppose he didn't add tobacco to the list because he himself was an inveterate smoker.

At the deepest level of historical connection, one might say at the point where economic substructure meets the reptile brain, the common denominator of globalized nonmedical drug use was the rise of limbic capitalism. By that I mean the reorientation of capitalist enterprise from basic services and durable goods to the more profitable business of providing transient but habitual pleasures, whether drugs or pornography or gambling or even sweet and fatty foods. In global terms limbic capitalism first became important in the age of transoceanic empire building. Were it not for the trade in sugar, tobacco, tea, and opium, there never would have been a British Empire, with all that entailed for modern history. Limbic capitalism has become even more conspicuous and lucrative in our own advanced (if that is the word) consumer societies. Entrepreneurs exploit evolved drives and then provide the goods and services to cope with the damage. Alcohol sells aspirin, cigarettes sell nicotine patches, sugar sells insulin, heroin sells Naltrexone, which costs addicted patients between $\$ 100$ and $\$ 150$ a month (Rawson et al. 2000). A recent book, Investing in Vice, concludes that the best, most recession-proof financial strategy is to buy a portfolio of "sin stocks," taking advantage of their relatively inflexible demand curves (Ahrens 2004). I would "double down" the bet by adding stocks of the companies that clean up after the sin companies. Logically, the demand curves for the two sorts of products are correlated. 
I can't explore all the ramifications of limbic capitalism. But I have tried to show how biological, genetic, epidemiological, and historical evidence has given momentum and credibility to the revitalized ATOD paradigm. That doesn't guarantee its permanent or universal triumph. In particular, alcohol may resist the trend. The alcoholic beverage industry has money, influence, and an argument-moderate consumption is healthful-that may continue to win privileges for its product. Time will tell. Invite me back thirty years hence, and I'll tell you whether Mr. ATOD's car has swerved back to the other side of the road.

\section{University of North Florida \\ dcourtwr@unf.edu}

\section{Notes}

1. For reasons of time, I omitted the section on genetics during the original talk.

2. The relationship between nicotine and caffeine is complex, but researchers have shown that rats chronically exposed to caffeine self-administer nicotine at higher-than-control levels. Compared to nonsmokers, heavy smokers prefer more heavily caffeinated beverages, e.g, coffee rather than tea. Other drugs shown to increase nicotine consumption in animals include pentobarbital, amphetamine, methadone, and heroin (Courtwright and Courtwright, forthcoming).

\section{REFERENCES}

Acker, C. 2002. Creating the American junkie: Addiction research in the classic era of narcotic control. Baltimore: Johns Hopkins University Press.

Ahrens, D. 2004. Investing in vice: The recession-proof portfolio of booze, bets, bombs, and butts. New York: St. Martin's Press.

Archer, J. 2003. A prison diary. New York: St. Martin's Press.

Armstrong, E. M. 2003. Conceiving risk, bearing responsibility: Fetal Alcohol Syndrome and the diagnosis of moral disorder. Baltimore: Johns Hopkins University Press.

Burnham, J. C. 1993. Bad habits: Drinking, smoking, taking drugs, gambling, sexual misbehavior, and swearing in American history. New York: New York University Press. 
Courtwright, A. M., and D. T. Courtwright. Forthcoming. "Alcohol, tobacco, and other drugs." Tobacco, ed. J. Goodman et al. Charles Scribner's Sons.

Courtwright, D. T. 2001a. Dark paradise: A history of opiate addiction in America. Cambridge, Mass.: Harvard University Press.

Courtwright, D. T. 2001b. Forces of habit: Drugs and the making of the modern world. Cambridge, Mass.: Harvard University Press.

Courtwright, D. T. 2005. "'Carry on smoking': Public relations and advertising strategies of American and British tobacco companies since 1950." Business History 47: 421-32.

Crothers, T. D. 1902. Morphinism and narcomanias from other drugs: Their etiology, treatment, and medicolegal relations. Philadelphia: W. B. Saunders.

Ellickson, P. et al. 2002. "Does early smoking signal later problems?" RAND Research Highlights. http://www.rand.org/publications/RB/RB4547/.

Gerstein, D. R., and H. J. Harwood, eds. 1990. Treating drugs problems, vol. 1: A study of the evolution, effectiveness, and financing of public and private drug treatment systems. Washington, D.C.: National Academy Press.

Gottfredson, M. and T. Hirschi. 1990. A general theory of crime. Stanford: Stanford University Press.

Haggard, H. W., and E. M. Jellinek. 1942. Alcohol explored. Garden City, N.Y.: Doubleday.

Kandel, D. B., ed. 2002. Stages and pathways of drug involvement: Examining the gateway hypothesis. Cambridge: Cambridge University Press.

Keeley Institute. 1921. "Liquor is the worst handicap in every game of life." [advertising sewing kit] Advertising Ephemera Collection, Special Collections Library, Duke University.

Kerr, N. 1887. Wines: Scriptural and ecclesiastical, 2nd ed. London: National Temperance Publication Depot.

Krueger, H., N. B. Eddy, and M. Sumwalt. 1943. The pharmacology of the opium alkaloids, part 2, supplement no. 165 to the Public Health Reports. Washington, D.C.: United States Public Health Service.

Krystal, J. H. et al. 2001. "Naltrexone in the treatment of alcohol dependence." New England Journal of Medicine 345: 1734-39.

Leshner, A. I. 1997. "Addiction is a brain disease, and it matters." Science 278: 45-47.

McClellan, A.T. et al. 2001. "Drug dependence, a chronic mental illness." JAMA: The Journal of the American Medical Association 284: 1689-95.

Nestler, E. J. and R. C. Malenka. 2004. “The addicted brain." Scientific American 290, no. 3 (March): 78-85.

Petry, N. M. 2002. "How treatments for pathological gambling can be informed by treatments for substance use disorders." Experimental and Clinical Psychopharmacology 10: 184-92. 
Rawson, R.A. et al. 2000. "Addiction pharmacotherapy 2000: New options, new challenges." Journal of Psychoactive Drugs 32: 371-78.

Roizen, R. 2004. "How does the nation's 'alcohol problem' change from era to era? Stalking the social logic of problem-definition transformations since Repeal." Pp. 61-87 in Altering American consciousness: The history of alcohol and drug use in the United States, 1800-2000, ed. S. W. Tracy and C. J. Acker. Amherst: University of Massachusetts Press.

Room, R. 2004. "Alcohol and harm reduction, then and now." Paper at the International Conference on Drugs and Alcohol in History, Huron University College, London, Ontario, May 14, 2004.

Satel, S. 2002. "Is drug addiction a brain disease?" Pp. 55-63 in One Hundred Years of Heroin, ed. D. Musto et al. Westport, Conn.: Auburn House.

Tate, C. 1999. Cigarette wars: The triumph of "the little white slaver." New York: Oxford University Press.

Towns, C. B. 1915. Habits that handicap: The menace of opium, alcohol, and tobacco, and the remedy. New York: Century.

Tracy, Sarah. 2005. Alcoholism in America: From Reconstruction to Prohibition. Baltimore: Johns Hopkins University Press.

White, William. 1998. Slaying the Dragon: The History of Addiction Treatment and Recovery in America. Bloomington, Ill.: Chestnut Health Systems/ Lighthouse Institute.

Woiak, Joanne. 1998. "Drunkenness, degeneration, and eugenics in Britain: Anti-alcohol reform in Caleb Saleeby's program of preventive eugenics." Paper presented at the American Association for the History of Medicine, Toronto. 
The Social History of Alcohol and Drugs 20 (2005): 138-40.

\section{Addiction Science, History, and the ATOD Paradigm: A Reply to Hasso Spode, IAN Tyrrell, AND JAMES Mills}

\section{David T. Courtwright}

Hasso Spode and Ian Tyrrell are right to point out that, in a global perspective, the debate over addiction began earlier and assumed more complex forms than indicated in my sketch. It is true too that ideas about addiction were "culturally lagged" - a useful phraseand that the question of ATOD unity begged another issue, namely, where addiction was existentially located. So, yes, the situation a century ago was messier than the inebriety paradigm alone would indicate. Hence my circumspection in limiting the discussion to Britain and North America, places where the unified inebriety concept temporarily dominated medical opinion.

"Medical opinion" was not, as James Mills reminds us, solely the domain of physicians and scientists. My own lay example, Charles Towns, was a salesman who overcame initial skepticism from the medical establishment and who became, for a time, a respected figure in the treatment community. In Britain and North America, however, physicians like Norman Kerr or Thomas Crothers did most of the technical, etiological writing on drugs and the nervous system. Ultimately, it was their failure to create a testable empirical basis for the unified inebriety theory, to advance beyond the vague nineteenth-century concepts of neurasthenia, diathesis, and degeneration, that made the concept vulnerable to scientific and corporate counterattack in the mid-twentieth century.

Today the revitalized ATOD paradigm extends well beyond the 
Anglo-American world. It has gone global, as has the scientific enterprise itself. On-line journals carry the latest discoveries about neural pathways, receptors, genetic predispositions, drug synergisms, and gateway epidemiology to researchers and public health officials around the world. Tyrrell captured the spirit of my essay when he suggested that historians can apply these same medical-scientific insights to past patterns of drug use, while avoiding biological reductionism by showing the play of cultural, geographic, and social forces.

All three commentators note that I emphasized medical research discoveries in explaining the rise of the new ATOD paradigm. One reason for doing so is that the lack of biological evidence was a key reason why the old inebriety paradigm collapsed. Nineteenth- and early twentieth-century observers saw that addictive behaviors were like one another in important ways, such as compulsive use, withdrawal symptoms, craving, and relapse. Until the 1970s, however, no one could make neurochemical sense of why different substances produced similar intoxicating and addictive effects. That was the essential breakthrough, though external factors like growing concern over health risks or corporate malfeasance prepared the cultural soil onto which the seed of scientific insight fell.

When I wrote the lecture I knew that drug historians preferred the cultural soil to the scientific seed. Another reason for highlighting scientific advances was to bring them to the attention of an influential scholarly audience that seemed to be getting too comfortable in its social-constructionist ways. James Mills counters that "so much of what has gone before as authoritative data has, in fact, simply been morality or prejudice dressed up with the ribbons of science." Fair enough. But it is also fair to say that we now know more, and in more fine detail, about how various drugs actually affect the brain than we did in the Victorian era. There is progress in science, and that progress can be liberating. For too long drug historians have been like transportation historians writing separate monographs on cars, trucks, and motorcycles without knowing how internal combustion engines worked, or why they burned hydrocarbon 
fuels and generated pollution. Suspicion of scientific arrogance and imperialism ought not to prevent anyone from the selective appropriation of research insights, especially those that illuminate the common or synergistic features of drug action. My subversive advice: break history's last taboo. Take a hit of neuroscience. Just don't get addicted.

Tyrrell asks where the line on drugs should be drawn. My rule of thumb is to include any psychoactive substance that stimulates the mesolimbic dopamine system, the primitive neural substrate of pleasure and motivation. Thus cocaine and caffeine are both drugs, though one is good deal stronger than the other. Sugar is a special case. I don't consider sugar a drug per se, but it has often been made into a drug (alcohol) or used to sweeten drug preparations such as chewing tobacco or tea. A spoonful of sugar makes the alkaloid go down.

If drug history evolves toward the broader study of compulsive behaviors, such as gambling or even certain types of eating, I would be neither surprised nor perturbed. Cheese may not be "morphine on a cracker," as one activist has claimed, but we should remain open-minded about where research on the brain's pleasure centers will lead. Social history is about making connections. Medical science keeps suggesting new connections. Is it, for example, just a cultural coincidence that games of chance have long flourished in taverns, or that Las Vegas runs on booze, or that the Koran prohibits both alcohol and gambling? I don't know the answer. I do know that posing such questions will enrich our field, and align us with researchers who are expanding the boundaries of other disciplines.

University of North Florida

dcourtwr@unf.edu 